\title{
Research
}

Marcello Morciano, Katherine Checkland, Jonathan Hammond, Yiu-Shing Lau and Matt Sutton

\section{Variability in size and characteristics of primary care networks in England:}

\author{
observational study
}

\begin{abstract}
\section{Background}

General practices in England have been encouraged by national policy to work together on a larger scale by creating primary care networks (PCNs). Policy guidance recommended that they should serve populations of $30000-50000$ people to perform effectively.
\end{abstract}

\section{Aim}

To describe variation in the size and characteristics of PCNs and their populations.

\section{Design and setting}

Cross-sectional analysis in England.

\section{Method}

Using published information from January 2020, PCNs were identified that contained $<30000$, between $30000-50000$, and >50 000 people. Percentiles were calculated to describe variation in size and population characteristics. PCN composition within each commissioning region was also examined.

\section{Results}

In total, 6758 practices had formed 1250 PCNs. Seven hundred and twenty-six (58\%) $\mathrm{PCNs}$ had the recommended population of 30 000-50 000 people. Eighty-four (7\%) PCNs contained $<30000$ people. Four hundred and forty (35\%) PCNs contained $>50000$ people.

Thirty-four (3\%) PCNs comprised just one practice and 77 (6\%) PCNs contained $>10$ practices. Some PCNs contained more than double the proportions of older people and people with chronic conditions compared to other PCNs. More than half of the population were from very socioeconomically deprived areas in 172 (14\%) PCNs. Only six (4\%) of the 135 commissioning regions ensured all PCNs were in the recommended population range. All practices had joined a single PCN in three $(2 \%)$ commissioning regions.

\section{Conclusion}

More than $40 \%$ of the PCNs were not of the recommended size, and there was substantial variation in their composition and characteristics. This high variability between $\mathrm{PCNs}$ is a risk to their future performance.

\section{Keywords}

clinical commissioning groups; cross-

sectional studies; England; general practice; government; primary care networks; primary health care.

\section{INTRODUCTION}

In response to concerns about the sustainability of the current model of primary care delivery, NHS England announced its intention to create primary care networks (PCNs) in the NHS Long Term Plan. ${ }^{1}$ This was a further development of policy to encourage primary care providers to work 'at scale'.

PCNs are composed of individual GP practices, led by a clinical director lusually a GP). Prospective PCNs are required to submit a draft network agreement specifying their GP practice members, patient populations, and geographical coverage to their local clinical commissioning group (CCG), the majority of which commission primary care services locally on behalf of NHS England under a delegation arrangement. This process requires CCGs to negotiate the composition of some PCNs with GP practices and approve a local configuration that ensures $100 \%$ patient population coverage in each area. PCNs were officially established in July 2019, just 6 months after their initial announcement. ${ }^{3}$ A national list of PCNs and their members was published in November 2019 and updated in January 2020

$\mathrm{PCN}$ s have a range of intended functions and objectives including:

- orchestrating the employment and work of new primary care staff;

\section{Morciano, BA, MSc, $\mathrm{PhD}$, senior lecturer in health policy and economics; K Checkland BMedSci, MRCGP, MA(Econ), PhD, professor in health policy and primary care; $\mathbf{J}$ Hammond, BMedSci, MSc, PhD, research fellow health policy; Y-S Lau, BA, MSc, PhD, research fellow in applied health economics; M Sutton, BA, MSc $\mathrm{PhD}$, professor in health economics, Division of Population Health, Health Services Research and Primary Care, University of Manchester, Manchester.}

Address for correspondence

Marcello Morciano, Health Organisation, Policy
- ensuring the collaborative delivery of services beyond core general practice;

- facilitating closer relationships across a geographical area with other providers and community groups; and

- providing a stronger voice for primary care within the broader system.

PCNs will be required to deliver new services to their registered patients set out in seven national services specifications. ${ }^{4}$ CCGs continue to be the de facto commissioners of primary care services, and will be responsible for monitoring PCN performance and supporting their development.

Guidelines stated that each PCN should contain between 30000-50000 registered patients in order to reflect 'natural communities ${ }^{5}$ and allow PCNs to perform their functions effectively. ${ }^{1,6}$ PCNs of $<30000$ patients were only anticipated to be approved by commissioners in 'exceptional circumstances'; those PCNs approved that had >50 000 people were expected to consider forming smaller neighbourhood teams in order to reflect the population size specified as desirable by the policy. ${ }^{7}$ In this article, it is considered how well this guidance has been adhered to by the examination of the variations in the size of the PCNs that have emerged. The variations in the demographic,

and Economics (HOPE) research group, Division of Population Health, Health Services Research and Primary Care, School of Health Sciences, University of Manchester, Manchester M13 9PL, UK.

Email: marcello.morcianodmanchester.ac.uk Submitted: 25 February 2020; Editor's response: 30 March 2020; final acceptance: 19 May 2020. (C)The Authors

This is the full-length article (published online 3 Nov 2020) of an abridged version published in print. Cite this version as: Br J Gen Pract 2020; DOI: https://doi.org/10.3399/bjgp20X713441 


\section{How this fits in}

New primary care networks (PCNs) have been created in England to encourage collaboration between groups of general practices. Presented here are findings from the first independent national evaluation of the size and characteristics of PCNs. National policy specifies that PCNs would be most effective if they served $30000-50000$ people. Only $58 \%$ of the PCNs that have emerged are within this range, with $7 \%$ being smaller and $35 \%$ being larger than the recommended population size. Some PCNs face particular challenges, such as those with twice as many older people and people with chronic conditions as other PCNs. The differences in size and characteristics of PCNs will affect their performance, governance, and management. PCNs are the primary vehicle through which new investment is being channelled into general practices. It is therefore important to understand the factors that might affect their ability to utilise that investment effectively and equitably.

socioeconomic, and epidemiological pressures they face are also summarised. Finally, the configurations of PCNs that have emerged within CCGs are described, as are the new commissioner-provider relationships that have developed.

\section{METHOD}

Information was obtained from the NHS Digital website about the PCN that each GP practice in England was a core partner of. ${ }^{8}$ This information was linked to data from NHS Digital on the size and age composition of the populations registered with each GP practice in January 2020.9 To avoid the loss of 44 practices that did not report data in January 2020, population counts were filled in using the most recently reported information. One of the 6758 GP practices in the PCN membership file could not be matched to the registered population data and was removed.

PCNs were classified into three groups according to whether their population size was below, within, or above the recommended size of $30000-50000$ persons. Variation in population size and numbers of GP practices across PCNs is presented.

The variation across PCNs was quantified by displaying the tenth, the median, and the 90th percentiles for summary measures of the demographic, economic, and epidemiological pressures they face. The decile ratio was also computed. ${ }^{10}$

The proportion of patients aged $\geq 65$ years was computed for each PCN using the registrations data. 9 Data on numbers of patients by GP practice and Lower-level Super Output Area (LSOA) were merged to information on LSOA rurality ${ }^{11}$ and deprivation, ${ }^{12}$ and the percentages of the population living in rural areas and in the least and most deprived $20 \%$ of areas were calculated.

Prevalence data were obtained for practices from the 2017/2018 Quality and Outcomes Framework (QOF), ${ }^{13}$ and aggregated to PCN level using population weights. Eight conditions were focused on representing a range of conditions likely to affect patients covered by the service specifications that the PCNs will need to deliver.

The ratio of weighted to unweighted registered population was calculated based on data available on GP practice payments made in the financial year April 2018 to March 2019.14 This measure of relative workload is based on the Global Sum weighted capitation formula. ${ }^{15}$ It accounts for age and sex, patient need, list turnover, market forces, rurality, and patients in nursing and residential homes.

The data were then aggregated into 135 CCGs, as of April 2020,16 to examine the variation in the commissioner-provider relationships that has emerged. The number of PCNs in each CCG and the percentage of $\mathrm{PCNs}$ in the target population range were counted. The percentages of the CCG's population and practices within their largest PCN were calculated. The ratio of the largest PCN to the smallest for the 132 CCGs with at least two PCNs was also computed.

\section{RESULTS}

There were 1250 PCNs in January 2020. In Figure 1, the frequency histogram of the population size of each PCN is illustrated. Approximately six out of 10 (58\%) PCNs were in the recommended population range of $30000-50000$. The mean (median) size of a PCN is 48000 (44000) registered patients. About $7 \%$ of $\mathrm{PCNs}$ cover a list size population $<30000$, with $1 \%$ of the total covering $<24000$ patients. About $35 \%$ of PCNs have a population above the recommended range, with $5 \%$ of the total having $>80000$ registered patients.

On average, a PCN is composed of five practices, with considerable variation around the mean (Figure 2). One-tenth of $\mathrm{PCNs}$ are formed by three practices or 
Figure 1. Variation in the size of the registered population across $\mathrm{PCNs}{ }^{a}$

${ }^{a}$ The decile ratio is the ratio of the upper bound value of the ninth decile (that is, the $10 \%$ of PCNs with highest values, $P 90=69200$ patients) to that of the first ( $P 10=31100$ patients). $P C N=$ primary care network. $P 10=$ tenth percentile score. $P 90=90$ th percentile score.

Figure 2. Variation in the number of GP practices across PCNs.a

${ }^{a}$ The decile ratio is the ratio of the upper bound value of the ninth decile (that is, the $10 \%$ of PCNs with highest values, $P 90=3$ practices) to that of the first ( $P 10=8$ practices). $P C N=$ primary care network. $P 10=$ tenth percentile score. $P 90=90$ th percentile score.

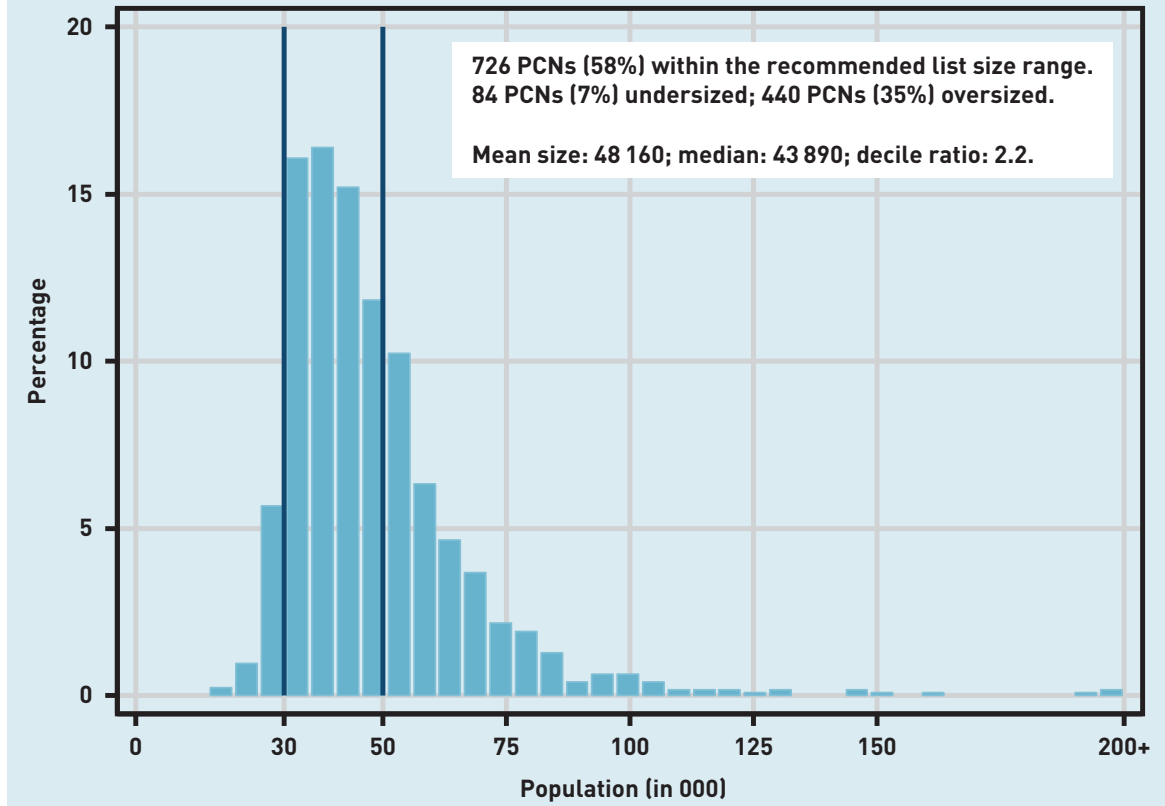

less. Another tenth is composed of eight or more practices. At the extremes, $34 \mathrm{PCNs}$ comprise a single practice while 77 PCNs contain $>10$ practices.

Figure 3 illustrates the joint variation in size of registered population and number of member practices across PCNs. Although the two measures of size are correlated, there is substantial variation in both dimensions. Even within the suggested range of population size of $30000-50000$

there is much variation in the number of practices involved. Some peculiar PCN configurations, with a high number of patients and a relatively small number of practices, are located outside the range. For example, there are PCNs that contain only two (super-)practices but cover nearly 100000 people. Similarly, there are PCNs with a large number of patients covered by a multitude of GP practices.

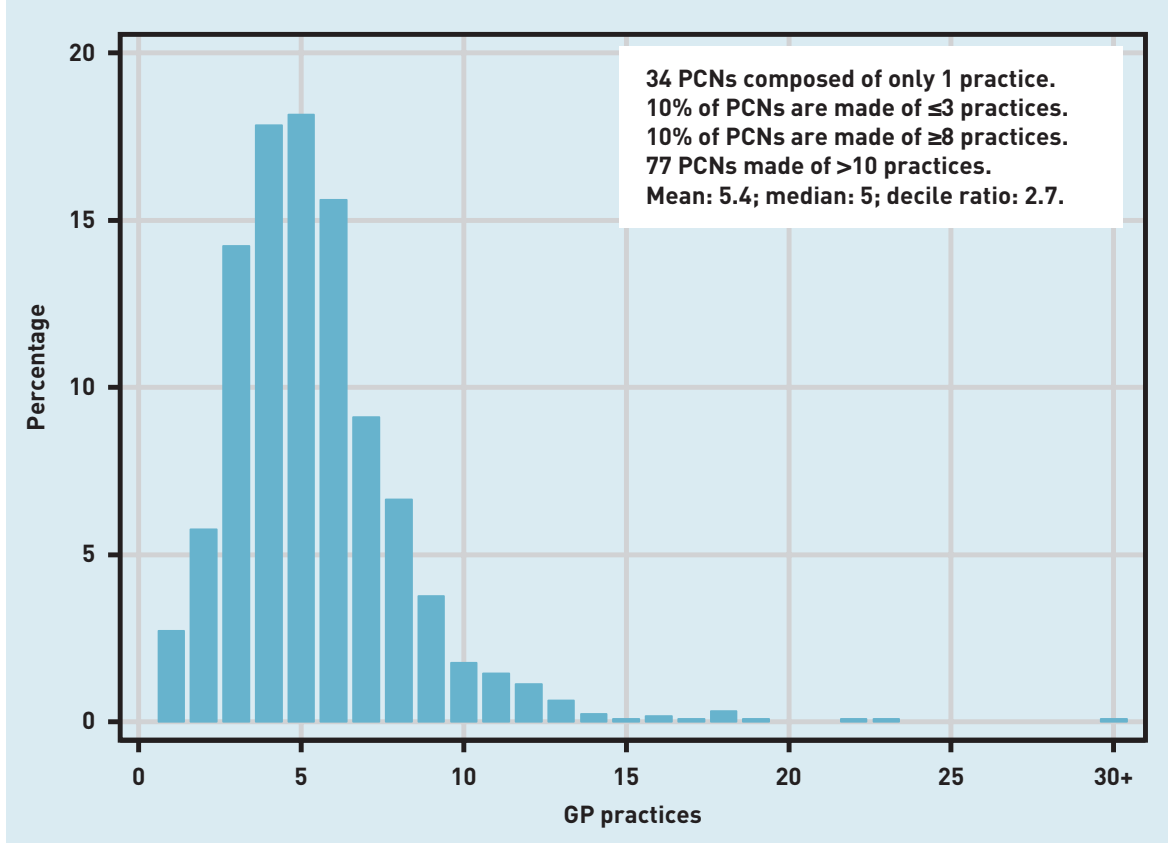




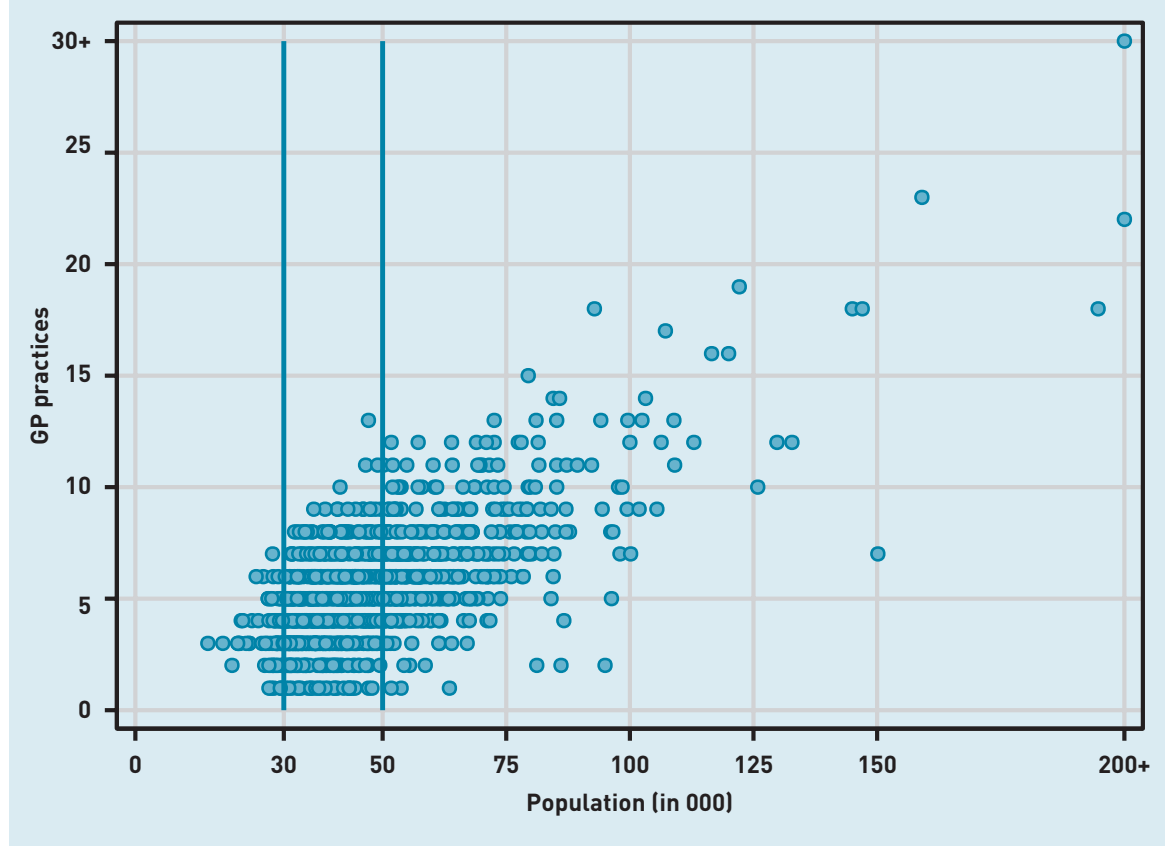

Figure 3. Scatterplot of number of GP practices and size of registered population across primary care networks.
Table 1 shows the variation across PCNs in some key characteristics of the population they cover. There is substantial variation in the challenges that PCNs will face to meet the needs of their populations. On average, about $18 \%$ of patients in PCNs are aged $\geq 65$ years. However, when ranking

\section{Table 1. Variation in the demographic, socioeconomic, and epidemiological characteristics across PCNs}

\begin{tabular}{|c|c|c|c|c|c|}
\hline Population characteristic, \%a & Mean & $\begin{array}{c}\text { 10th } \\
\text { percentile }\end{array}$ & Median & $\begin{array}{c}\text { 90th } \\
\text { percentile }\end{array}$ & $\begin{array}{l}\text { Decile } \\
\text { ratio' }^{\text {b }}\end{array}$ \\
\hline Aged $\geq 65$ years & 17.7 & 9.2 & 18 & 25.6 & 2.8 \\
\hline Living in rural area & 17.2 & 0 & 2.5 & 60.1 & - \\
\hline Living in deprived area ${ }^{c}$ & 20.6 & 0 & 12.8 & 55.6 & - \\
\hline Living in affluent area ${ }^{c}$ & 19.2 & 0.3 & 12.3 & 50.3 & - \\
\hline \multicolumn{6}{|l|}{ Diagnosed with: ${ }^{\text { }}$} \\
\hline Chronic obstructive pulmonary disease & 1.9 & 1.0 & 1.9 & 2.9 & 2.9 \\
\hline Chronic kidney disease & 4.1 & 2.2 & 4.1 & 6.2 & 2.8 \\
\hline Diabetes & 7.0 & 5.1 & 7.0 & 8.8 & 1.7 \\
\hline Cardiovascular disease & 1.1 & 0.8 & 1.1 & 1.5 & 1.8 \\
\hline Hypertension & 14.1 & 10.0 & 14.4 & 17.6 & 1.8 \\
\hline Stroke and transient ischaemic attack & 1.8 & 1.0 & 1.8 & 2.5 & 2.6 \\
\hline Serious mental illness & 1.0 & 0.7 & 0.9 & 1.3 & 2.0 \\
\hline Obesity & 8.1 & 5.0 & 8.0 & 11.0 & 2.2 \\
\hline Workload index ${ }^{e}$ & 1.01 & 0.9 & 1.01 & 1.11 & 1.2 \\
\hline
\end{tabular}

a Unless otherwise stated. ${ }^{b}$ The decile ratio is the ratio of the upper bound value of the ninth decile (that is, the $10 \%$ of PCNs with highest values, P90) to that of the first (P10). cPopulation living in the $20 \%$ most deprived/affluent

Lower-level Super Output Areas according to the 2019 Index of Multiple Deprivation. 'Statistics computed over 1249 PCNs using prevalence data from the 2017/18 Quality and Outcomes Framework. ${ }^{e}$ Weighted registered population divided by unweighted registered population based on the weighted capitation formula. $P 10=$ tenth percentile score. P90 $=90$ th percentile score. $P C N=$ primary care network.
PCNs according to the proportion of older people they cover, a 2.8-fold difference is found between the tenth (9.2\%) and the 90 th (25.6\%) percentile.

Marked differences were found when PCNs were ranked according to their coverage of patients living in rural areas and associated area levels of deprivation. Although about $10 \%$ of PCNs cover populations that are almost entirely located in urban or deprived areas, another 10\% cover patients largely (>60\%) living in urban areas. Similarly, there are some PCNs that cover populations mainly living in the most deprived areas 190th percentile score $=55.6 \%$ ) whereas others tend to have patients living in the most affluent areas.

PCNs differ also in terms of the needs of the patients they cover. One-tenth of PCNs face prevalence rates ranging between 70\% (for diabetes) and almost three times lower (for chronic obstructive pulmonary disease [COPD] and chronic kidney disease [CKD]) than the highest tenth. The workload factor in the lowest tenth of PCNs is on average $20 \%$ lower than that observed in the highest tenth.

For a stratification of these key characteristics by PCN size, see Supplementary Table S1. Undersized PCNs tend to serve patients living in rural areas who are considerably older, with higher prevalence rates of diagnosed conditions than patients served by PCNs that are above or within the recommended population range.

The median CCG deals with six PCNs (mean of 9.3), but with significant variation ranging from one PCN (three CCGs) to $>42$ PCNs in one CCG (Table 2). The number of PCNs in one-tenth of CCGs is 4.5 times lower than that in another tenth. Over half of the PCNs in a CCG are within the list size range, with a three-fold difference from the lowest tenth (25\%) to the highest tenth (80\%). Only six of the 135 CCGs managed to get all PCNs in the targeted list size. In seven CCGs, all PCNs are outside the expected list size range.

On average, around one-quarter of a CCG's population are covered by its largest $P C N$, with large dispersion around this figure (decile ratio $=4.2$ ). Similarly, onequarter of practices in a CCG are associated with the largest PCN. However, one-tenth of CCGs have about $11 \%$ of the total practices nested in the largest PCN, whereas another tenth of CCGs have $40 \%$ of their practices affiliated with the largest PCN. Among the 132 CCGs with at least two $\mathrm{PCNs}$, the largest PCN is approximately 2.4 times the size of the smallest, but with 


\section{Table 2. Variation in the PCN configurations across CCGs}

\begin{tabular}{|c|c|c|c|c|c|}
\hline & Mean & P10 & Median & P90 & $\begin{array}{l}\text { Decile } \\
\text { ratio }^{a}\end{array}$ \\
\hline PCNs, $n$ & 9.3 & 4.0 & 6.0 & 18.0 & 4.5 \\
\hline PCNs in target population size range, $\%$ & 54.8 & 25.0 & 57.1 & 80.1 & 3.2 \\
\hline CCG population in CCG's largest PCN, \% & 24.2 & 9.6 & 21.7 & 40.4 & 4.2 \\
\hline CCG practices in CCG's largest PCN, \% & 25.5 & 10.8 & 22.2 & 40.0 & 3.7 \\
\hline Ratio of largest to smallest PCN population in the CCG & 2.4 & 1.5 & 2.2 & 3.5 & 2.4 \\
\hline \multicolumn{6}{|c|}{$\begin{array}{l}\text { The decile ratio is the ratio of the upper bound value of the ninth decile (that is, the } 10 \% \text { of PCNs with highest } \\
\text { values, P90) to that of the first (P10). }{ }^{\circ} \text { Analysis restricted to } 132 \mathrm{CCG} \text { (over 135) with at least two PCNs. } \\
C C G=\text { clinical commissioning group. P10 = tenth percentile score. P90 } 90 \text { th percentile score. PCN = primary care } \\
\text { network. }\end{array}$} \\
\hline
\end{tabular}

considerable variation around this figure (decile ratio $=2.4$ )

\section{DISCUSSION \\ Summary}

The precise form and purpose of PCNs has evolved since their initial announcement and is still under negotiation. It is likely, however, that PCNs will become a feature of the inter-organisational landscape of the English NHS for years to come, and represent a network model that is part of a broader trend of organisational delivery.

The aim of this study was to describe the variation in size and characteristics of PCNs and their populations in the context of policy recommendations about the population size that was required to perform effectively. It was found that approximately $60 \%$ of $\mathrm{PCN}$ are within the recommended range of 30 000-50 000 population. A significant proportion (35\%) were above the range, while $7 \%$ were undersized. PCNs vary also in terms of the number of associated GP practices. There is a range of different organisational structures, from PCNs composed of a single practice loften a super-practicel to PCNs composed of $>10$ practices. Although large PCNs tend to be formed by a larger number of practices, this is not always the case. Some peculiar PCN configurations have emerged, most notably the case of PCNs composed of a relatively small number of practices covering large populations. Marked differences were also documented in the sociodemographic and epidemiological pressures that PCNs face, with undersized PCNs serving higher proportions of people living in rural areas, predominantly older people, ${ }^{17}$ and people with associated healthcare needs.

One particular implication concerns the relationships between PCNs and their commissioners. CCGs continue to be the (delegated) purchasers of primary care services in most areas, and so will be responsible for operationalising the PCN contract locally and monitoring PCN performance. ${ }^{3}$ They may also have a role in the future in distributing incentive payments associated with the investment and impact funding' stream, and will continue to be responsible for negotiating existing additional local contracts (known as locally enhanced services').

The ability of CCGs to perform their core functions of purchasing, regulation, and financing may depend on the relative sizes of the PCNs that have emerged in their area. This study has documented some of these differences, and noted that the bargaining power may be stronger for large PCNs in some CCGs. Where there are few PCNs, the new provider groups may be able to take advantage of the strength of their position in local negotiations. Where there are multiple PCNs, the purchasers will be able to undertake benchmarking and make the most of the purchasing power. However, it may also be the case that some of those PCNs above or below the suggested size were able to successfully negotiate their composition because they possessed sufficient power to do so, and these PCNs may enjoy relatively higher degrees of influence in their local systems.

\section{Strengths and limitations}

This article presents findings from the first independent national evaluation of the size and characteristics of 1250 PCNs using the latest released (January 2020) administrative data, made available through NHS England combined with other administrative sources. To avoid the loss of GP practices that had missing values in one of the indicators used for the analysis, gaps were filled in using the latest information available. Although this approach may not accurately reflect current practice in the context of rapid changes in population size and structures, it permitted a fuller representation of PCNs in England. Only one GP practice was omitted from the analysis; this practice served mainly asylum seekers and refugees, and as such it was not possible to gather population characteristics for this practice.

Practices were treated with the same surgery codes as single providers. In other words, it was not possible to identify, and treat as a single entity, pre-existing practice ventures (for example, 'super partnerships') whose members have retained separate surgery codes. ${ }^{2}$ This would reduce the number of delivery units within a PCN, 
affecting the results presented in Figures 2 and 3. However, there is no up-to-date national dataset on these superpartnerships.

\section{Comparison with existing literature}

A descriptive analysis of the variation in population size of PCNs has been published online. ${ }^{18}$ That analysis was extended by this study in several ways. First, variation in size with respect to list size population and number of practices involved was documented systematically. Second, the analysis was extended to a range of sociodemographic and health indicators. Third, some of the complexities CCGs may face in operationalising their roles as local commissioner, regulator, and financer were highlighted.

\section{Implications for research and practice}

The variation in the size, composition, and characteristics of PCNs is a consequence of the decision to allow practices to choose the local configuration of their PCN lalbeit with CCG oversight). ${ }^{19}$ This may help to ensure that there are good collaborative relationships between the constituent members. However, at present, little is known about practice-level satisfaction with local PCN arrangements or the strength of inter-practice relationships. These will be crucial to the delivery of collaborative services in the future.

The variability documented also creates considerable challenges for all parties involved. PCNs will face different organisational challenges in delivering services contingent on their size, the characteristics of the populations they serve, and the delivery units they will contain. Furthermore, CCGs are likely to face a variety of commissioner-provider relationships with newly developed PCNs. For example, one of the intended roles for PCNs is to deliver services collaboratively between practices, working closely with other providers such as community service providers and voluntary sector organisations. The configuration of PCNs in a given local area will materially affect the development of such collaborations, as large providers may be required to engage with multiple PCNs, which may differ significantly in their organisation and ways of working.

CCGs are working in a rapidly changing context, with many merging to form larger groups $^{20}$ and some uncertainty around their role in newly developing integrated care systems. ${ }^{21}$ Research suggests effective commissioning of primary care services requires detailed local knowledge of practices and populations. ${ }^{22}$ Relationships between commissioners and their local PCNs will therefore be crucial in determining the outcomes associated with the new policy. This analysis suggests that there will be significant variation in the workload connected with the development and maintenance of these important relationships.

Research Programme (reference numbe PR-PRU-1217-20801). The views expressed are those of the authors and not necessarily those of the NIHR or the Department of Health and Social Care.

\section{Ethical approval}

Ethical approval was not required for this study.

\section{Provenance}

Freely submitted; externally peer reviewed.

\section{Competing interests}

The authors have declared no competing interests.

\section{Acknowledgements}

The authors are grateful to the wider team members and the advisory group for their suggestions in all phases of the research.

\section{Open access}

This article is Open Access: CC BY-NC 4.0 licence (http://creativecommons.org/ licences/by-nc/4.0/).

\section{Discuss this article}

Contribute and read comments about this article: bjgp.org/letters 


\section{REFERENCES}

1. NHS. The NHS Long Term Plan. 2019. https://www.longtermplan.nhs.uk/ publication/nhs-long-term-plan laccessed 27 Oct 2020).

2. Forbes $L J$, Forbes $H$, Sutton $M$, et al. How widespread is working at scale in English general practice? An observational study. Br J Gen Pract 2019; DOI: https://doi.org/10.3399/bjgp19X705533.

3. Fisher R, Thorlby R, Alderwick H. Briefing: understanding primary care networks. The Health Foundation, 2019. https://www.healthwatchswindon. org.uk/sites/healthwatchswindon.org.uk/files/Understanding\%20primary\%20 care\%20networks.pdf (accessed 27 Oct 2020).

4. NHS England. Investment and evolution: Update to the GP contract agreement 2020/21-2023/24. 2020. https://www.england.nhs.uk/publication/investmentand-evolution-update-to-the-gp-contract-agreement-20-21-23-24 laccessed 27 Oct 2020).

5. NHS England. Primary Care Networks: Frequently asked questions. 2019. https://www.england.nhs.uk/wp-content/uploads/2019/04/pcn-faqs-000429.pdf (accessed 27 Oct 2020)

6. British Medical Association. The primary care network handbook. London, 2019. https://www.bma.org.uk/media/2144/bma-pcn-handbook-march-2020. pdf (accessed 27 Oct 2020).

7. NHS England. Primary Care Networks: frequently asked questions: second iteration. 2019. https://www.england.nhs.uk/wp-content/uploads/2019/03/pcnfaqs-may-2019.pdf (accessed 27 Oct 2020).

8. NHS Digital. Primary Care Networks (epcn). In GP and GP practice related data. https://digital.nhs.uk/services/organisation-data-service/data-downloads/ gp-and-gp-practice-related-data laccessed 27 Oct 2020).

9. NHS Digital. Patients registered at a GP practice. https://digital.nhs.uk/dataand-information/publications/statistical/patients-registered-at-a-gp-practice laccessed 27 Oct 2020)

10. Gravelle H, Sutton M. Inequality in the geographical distribution of general practitioners in England and Wales 1974-1995. J Health Serv Res Policy 2001; 6(1): 6-13.

11. Office for National Statistics. Rural urban classification (2011) of Lower Layer Super Output Areas in England and Wales. 2018. https://data.gov.uk/dataset/ b1165cea-2655-4cf7-bf22-dfbd3cdeb242/rural-urban-classification-2011-oflower-layer-super-output-areas-in-england-and-wales laccessed 27 Oct 2020).
12. Ministry of Housing Communities \& Local Government. English indices of deprivation 2019. https://www.gov.uk/government/statistics/english-indices-ofdeprivation-2019 (accessed 27 Oct 2020).

13. NHS Digital. Quality and Outcomes Framework, achievement, prevalence and exceptions data 2018-19. 2019. https://digital.nhs.uk/data-and-information/ publications/statistical/quality-and-outcomes-framework-achievementprevalence-and-exceptions-data/2018-19-pas (accessed 27 Oct 2020).

14. NHS Digital. NHS payments to general practice - England, 2018/19. 2019. https://digital.nhs.uk/data-and-information/publications/statistical/nhspayments-to-general-practice/england-2018-19 (accessed 27 Oct 2020).

15. British Medical Association. Focus on the global sum allocation formula (Carr-Hill Formula). 2015. https://www.gloslmc.com/downloads/GPC\%20 Guidance \%20Docs/1507\%20Focus\%20on\%20the\%20Global\%20Sum\%20 Allocation\%20Formula\%20-\%20July\%202015.pdf (accessed 27 Oct 2020).

16. NHS Digital. Changes to organisation reference data: sustainability and transformation partnerships reconfiguration 2020. https://digital.nhs.uk/ services/organisation-data-service/changes-to-ord-stp-reconfiguration laccessed 27 Oct 2020).

17. Department for Environment, Food \& Rural Affairs. Rural population and migration. 2020. https://assets.publishing.service.gov.uk/government/ uploads/system/uploads/attachment_data/file/862320/Rural_population_and_ migration_Jan_20.pdf laccessed 27 Oct 2020).

18. Bostock N. More than 2 in 5 PCNs not on 'natural' scale envisaged by NHS England. 2020. https://www.gponline.com/2-5-pcns-not-natural-scaleenvisaged-nhs-england/article/1669532 (accessed 27 Oct 2020).

19. NHS England, British Medical Association. Investment and evolution: a five-year framework for GP contract reform to implement the NHS Long Term Plan. 2019. https://www.england.nhs.uk/wp-content/uploads/2019/01/ gp-contract-2019.pdf laccessed 27 Oct 2020).

20. NHS Digital. Change summary - 2020 STP, CCG and Commissioning Hub reconfiguration. https://digital.nhs.uk/services/organisation-data-service/ change-summary---stp-reconfiguration\#what-we-are-changing-on-1 april-2020 (accessed 27 Oct 2020)

21. British Medical Association. Briefing: integrated care systems. 2019. https:// wuw.bma.org.uk/media/1978/bma-integrated-care-systems-briefing-jan-19. pdf (accessed 27 Oct 2020).

22. Checkland K, McDermott I, Coleman A, et al. Planning and managing primary care services: lessons from the NHS in England. Public Money \& Management $2018 ; \mathbf{3 8 ( 4 ) : ~} 261-270$ 